\title{
A retrospective evaluation of the association between potentially inappropriate prescribing and adverse drug reactions among hospitalized elderly Nigerians
}

\author{
Ajibola Sule Saka ( $\square$ sulsak01@yahoo.com ) \\ Frasia Oosthuizen \\ University of KwaZulu-Natal College of Health Sciences \\ Manimbulu Nlooto \\ University of KwaZulu-Natal College of Health Sciences
}

University of KwaZulu-Natal College of Health Sciences https://orcid.org/0000-0001-5521-4282

\section{Research article}

Keywords: adverse drug reaction, Beers criteria, elderly inpatient, potential inappropriate prescribing

Posted Date: October 1st, 2019

DOl: https://doi.org/10.21203/rs.2.15400/v1

License: (c) (i) This work is licensed under a Creative Commons Attribution 4.0 International License.

Read Full License 


\section{Abstract}

Background Potentially inappropriate prescribing is associated with adverse clinical outcomes in the elderly. The Beers Criteria were developed to improve the quality of medication prescribing and safety to the elderly. However, the nexus between the Criteria's potentially inappropriate medicines (PIMs) and adverse drug reactions (ADRs) remains controversial in clinical practice. This study aimed to evaluate the association between the 2015 American Geriatrics Society-Beers' (AGS-Beers) PIMs and ADRs among elderly inpatients. Methods A cross-sectional retrospective study was carried out among elderly patients aged $\geq 60$ years that were hospitalized between 1st January and 31st December 2016 at the internal medicine wards of a Nigerian University teaching hospital. Eligible elders that were hospitalized or died within 24 hours were excluded from the study. The medical records of eligible participants were randomly selected and information including patients' socio-demographics, medication and medical histories, and medicines utilization during hospitalization were extracted from the records. Two clinical pharmacists evaluated the medical charts for PIMs using the 2015 AGS-Beers Criteria and ADRs using the Naranjo algorithm. Bivariate analyses and subsequently, a binary logistic regression, were carried out to determine the association between independent variables and $A D R s$ with $P<0.05$ being considered significant. Results A total of 268 participants mean age, 70.53 (8.22) years were evaluated. According to the AGSBeers Criteria, 32.1\% (86/268) received at least one PIM, 13.8\% (37/268) experienced 43 ADRs during hospitalization of which diclofenac was the most implicated medication for it $(8 / 43,18.6 \%)$. The AGSBeers' PIMs were not associated with ADRs in the bivariate analysis $(p=0.24)$. The diagnoses of musculoskeletal disorders $(\mathrm{OR}=7.38,95 \% \mathrm{Cl}=2.68-20.34, \mathrm{p}<0.001)$ and the use of anticholinergic medications $(\mathrm{OR}=4.02,95 \% \mathrm{Cl}=1.04-15.58, \mathrm{p}=0.04)$ were significantly associated with $A D R s$ in the logistic regression. Conclusion The elderly inpatients experienced ADRs which were associated with diagnoses of musculoskeletal disorders and anticholinergic medications but not the 2015 AGS-Beers' PIM in the Nigerian teaching hospital. Keywords: adverse drug reaction, Beers criteria, elderly inpatient, potential inappropriate prescribing Running title: Potential inappropriate prescribing and adverse drug reactions in elderly

\section{Background}

Population ageing demands cost-effective healthcare practices that will assure the safety of the elderly and maximize their well-being [1]. Adverse Drug Reactions (ADRs) present a safety concern in the elderly due to its associations with increased morbidity, mortality and healthcare costs [2]. Literature suggests that at least $10 \%$ of elderly experience ADRs either as inpatients or as outpatients [3]. Simple interventions that can reduce ADRs in this group of population is therefore of utmost importance.

Although many factors including age, comorbidity, polypharmacy and a diagnosis of heart failure have been associated with ADRs in the elderly, the prescribing of potentially inappropriate medicines (PIMs) appears to be consistently reported in the literature [2,4-7]. The PIMs are medications with higher risks of causing harms or less therapeutic effects among the elderly in the presence of safer and more effective alternatives [8]. The Beers Criteria and the Screening Tool of Older People's Prescriptions and Screening 
Tool to Alert to Right Treatment (STOPP/START Criteria) are amongst the explicit criteria developed to improve the safety of medication in the elderly by providing lists of PIMs to guide physicians' prescribing [8-10].

The Beers Criteria which were initially developed in the 1990s has been revised as more evidence unfold aimed at mitigating preventable ADRs and improving clinical outcomes among the elderly [8]. However, there is no conclusive evidence to show that the Criteria have achieved this goal in clinical practice because reports of associations between the earlier itinerary of the Criteria and ADRs are inconsistent and sometimes contradictory. A few studies among elderly Europeans, specifically in France and Italy that evaluated the association between the explicit criteria PIM list and ADRs found no association $[11,12]$ while studies among the Americans and Brazilians contradicted this negative finding [13, 14]. Few studies that compared the association between the Beers Criteria, STOPP/START criteria and ADRs found the latter PIMs to be better associated with ADRs among the elderly than the former $[5,15]$. Although, most of these previous studies applied the earlier versions of the Beers Criteria which have many shortcomings, the controversy remains even with the major review the Criteria have undergone since its adoption by the American Geriatrics Society in 2012. This is because a few studies that applied the 2012 American Geriatrics-Beers (AGS-Beers) associated its PIM list with ADRs and identified it as a predictor of mortality $[16,17]$, while many other studies that used the same version of the Criteria found no associations among the study populations [18-20].

The 2015 AGS-Beers Criteria have incorporated new classifications including the PIMs to be avoided due to non-anti-infective drug-drug interactions (DDIs), the drug-disease or drug-syndrome interactions, or to be avoided or have their dosages reduced due to level of kidney functions in the elderly, in addition to the traditional classification of "independent of diagnosis" [8]. Medications without sufficient evidence to be regarded as PIMs were recommended for cautious use in the Criteria. There is, however, a dearth of information concerning the association between this latest itinerary of the AGS-Beers Criteria and ADRs among the elderly. In Nigeria, studies have applied the Beers Criteria to screen for PIMs without exploring the clinical outcomes associated with the prescription of such medications [21-23]. This study aimed to evaluate the prevalence of ADRs and to determine the association between the 2015 AGS-Beers' PIMs and ADRs among hospitalized elderly in Nigeria.

\section{Methods}

\section{Study design and setting.}

This study was a cross-sectional retrospective evaluation of ADRs among hospitalized elderly, using a medical chart review at the internal medicine wards of a public University teaching hospital, in Southwest, Nigeria. The hospital which is 205 -bedded serves as a referral centre for many healthcare facilities in the region and had a number of geriatricians consulting in the medical wards at the time of this study.

\section{Study population/Eligibility Criteria}


Patients aged $\geq 60$ years that were hospitalized in the internal medicine wards of the hospital between $1^{\text {st }}$ January and $31^{\text {st }}$ December 2016 were eligible for inclusion in the study. In Nigeria, adults aged $\geq 60$ years are recognized as elderly in line with the United Nations cut-off and this was consistent with studies in many low and middle-income countries $[4,17,19,24]$. Eligible participants with incomplete sociodemographic information, discharged or transferred to another level of care, died within 24 hours of hospitalization, readmitted within the study period or on chemotherapeutic agents were excluded from this study. The data collection was carried out between $13^{\text {th }}$ April and $30^{\text {th }}$ July 2017.

\section{Selection of participants}

Figure 1 depicts the selection process of the participants. The study participants were identified from the hospital admission records. The eligible participants' medical record numbers were listed, and the included records selected using a simple non-blinded randomization technique with the aid of computergenerated random numbers. Included records with missing data were deleted before analysis.

\section{Sample size calculation}

The sample size was calculated based on the population of 846 elderly patients that were hospitalized at the internal medicine wards within the study period using the hospital admission records. Using this total population with a margin error of $5 \%$, a power of $95 \%$ and $50 \%$ response distribution yielding a minimum sample size of 265 , with additional $10 \%$ being added for attrition resulting in 292 participants for the maximum sample size as computed using a formula previously described [25].

\section{Data collection}

With the help of a trained research assistant, the selected records were retrieved and information including patients' socio-demographics, medical and medication histories, medicine utilization during hospitalization and duration of hospital stay were extracted using the researchers' designed checklist. The complexity of the patients' health conditions was determined using the Charlson's comorbidity index [26]. The patients' specific laboratory data including serum creatinine $(\mathrm{mg} / \mathrm{dL})$ or estimated glomerular filtration rate (eGFR) $\mathrm{mL} / \mathrm{min}$ ) calculated using the Cockcroft-Gault formula were documented [27]. Platelet counts (cells $/ \mathrm{mm}^{3}$ ), level of potassium and sodium electrolytes $(\mathrm{mmol} / \mathrm{L})$ at hospitalization and during hospital stay (where available) were also extracted. Physicians' clinical judgment of ADR occurrence documented in the charts and the clinical decisions that were taken to mitigate the ADRs including the substitution of medication and reduction in doses were extracted from the review sheet.

\section{Study procedure}

\section{Measurement of ADRs}

A multifaceted approach including a detailed review of nursing and physicians' charts, laboratory data, and other clinical parameters was conducted. Attention was paid to patients' verbalized complaints documented in the charts. Radio-imaging data, such as ultrasound, echocardiography, and 
electrocardiogram parameters were however not considered for review because they were rarely ordered by the physicians. Potential ADRs were identified using the Institute for Healthcare Improvement (IHI) global trigger tool which has been found useful in retrospective evaluations of ADRs among inpatients in many healthcare settings [28].

Two clinical pharmacists independently assessed the ADRs using the Naranjo algorithm which was preferred to other tools for its high specificity and ease of use [29]. A further analysis was performed for only "definite", "probable" and "possible" ADR categories. The assessors also agreed on the causality of the ADRs. Where there were disagreements between the assessors, it was referred to a physician and consensus were reached. This study evaluated the PIMs for both predictable and unpredictable ADRs but determined the association for the predictable only.

Assessment of PIMs

The appropriateness of medication use during hospitalization was assessed using the 2015 AGS-Beers Criteria. The PIMs of "independent of diagnosis", to be avoided due to drug-disease or drug-syndrome interactions to non-anti-infective DDIs and those to be avoided or have their doses reduced due to the level of kidney functions in elderly were evaluated. The strong anticholinergics listed in the Criteria were evaluated. The prevalence of medications that increase falls risks in the elderly according to the AGS clinical practice guidelines on fall prevention was also assessed [30].

\section{Data management and analysis}

The data were fed into the Statistical Packages for the Social Sciences software (SPSS version 25) and were primarily analyzed using descriptive statistics. Participants with missing data were deleted before the analysis. Student's independent t-test was used to compare normally distributed continuous variables and the results were presented in means and standard deviations. Bivariate analyses and subsequently, a binary logistic regression, were carried out to determine the associations between categorical variables and ADRs. Independent variables reported being associated with ADRs in previous studies including gender, age, comorbidity index, PIMs, diagnoses of heart failure, chronic kidney diseases and musculoskeletal disorders, use of anticholinergics and Falls associated medications and duration of hospitalization [2,4-7] were included in the model. In line with previous studies, age $\geq 80$ years, comorbidity index $\geq 4$ and duration of hospital stay $\geq 12$ days were used as references in the categorization of the variables $(1,4,31)$. $P$-values $<0.05$ were considered significant.

\section{Ethical considerations}

This study was exempted from requiring patients' consent to participate by the Health Research Committees of the Department of Health, Province of Kwazulu-Natal under the reference HRKM090/17 KZ_2017RP 16_591 and the Olabisi Onabanjo University Teaching Hospital Health Research Ethics Committee under the reference OOUTH/HREC/97/2016. Permission to access the data set was obtained from the management of the study sites and the Heads of the Medical Departments in the hospitals. The 
University of KwaZulu-Natal Biomedical Research Ethics Committee approved the study under the reference (BE 591/16). Unique numbers were used to code the identity of the patients and the data were secured through a password. Access to the data was restricted to the authorized personnel only.

\section{Results}

Of the 292 included participants 91.8\% (268/292) were eventually analyzed, the remainder 8.2\% (24/292) with missing data were deleted before analysis.

\section{Characteristics of the study population}

Table 1 presents the baseline socio-demographic characteristics of the study participants. A total of 268 participants, mean age 70.53 (8.22) years (range $=60-95$ years) were evaluated with the majority being male $(146 / 268,54.5 \%)$.

\section{Prevalence of PIMs among the study population}

Table 2 presents the frequency of PIMs among the study population. Almost one-third of the evaluated participants $(86 / 268,32.1 \%)$ received at least one PIM of which $84.9 \%(73 / 86)$ was of "independent of diagnosis" category, $14.0 \%$ (12/86) received PIMs with potential drug-drug and drug-disease interactions and $1.2 \%(1 / 86)$ due to kidney function. Almost half of the PIMs $(39 / 86,45.3 \%)$ was known to increase fall risks in the elderly (Supplement Table1). The PIMs were significantly associated with gender $(p=0.049)$.

\section{Adverse drug reactions among the study population}

Table 3 presents the ADRs among the participants. The participants $(37 / 268 ; 13.8 \%)$ experienced 43 cases of ADRs during hospitalization, 51.2\% (22/43) of the ADRs affected the digestive system and diclofenac was implicated in $18.6 \%(8 / 43)$ of the cases.

Table 4 presents the factors associated with ADRs among the participants in the bivariate and logistic regression. There were no significant associations between the ADRs and AGS-Beers' PIMs $(p=0.24)$, chronic kidney diseases $(p=0.91)$ and congestive heart failure $(p=0.30)$ in the bivariate analyses. The mean ages of participants with ADRs (67.49 (7.81) years and without ADRs were significantly different (67.49 (7.81) years vs $71.02(8.20)$ years respectively $95 \% \mathrm{Cl}=0.69-6.37, \mathrm{p}=0.02)$ and the duration of admission was $2.22 \pm 1.58$ days vs $1.49 \pm 0.99$ days, respectively $(95 \% \mathrm{Cl}-1.11-0.35, \mathrm{P}<0.001)$.

\section{Discussion}

This study evaluated the prevalence of ADRs and determined the associations between it and the 2015 AGS-Beers PIMs among the elderly inpatients in Nigeria. The results of this study indicated that PIP was common during inpatient care with one in three elderly people receiving a PIM as defined by the 2015 
AGS-Beers Criteria. More than $10 \%$ of the participants experienced ADRs during hospitalization but this was not significantly associated with AGS-Beers' PIMs.

The prevalence of PIMs in this study (32.1\%) was lower than previously reported in the studies that applied the 2012 AGS-Beers Criteria among the hospitalized elderly in Italy (58.4\%) [18] and the 2015 version in China (53.5\%) [32]. The differences in the clinical practice guidelines and medicines availability in the countries may account for this observation. The high use of the PIMs could be because the physicians considered the use of PIMs to be justifiable in the health conditions of the evaluated patients.

The prevalence of ADRs in this study (13.8\%) was similar to $13.2 \%$ reported among the elderly inpatients in England [33] and consistent with the global average in this population [3]. It was however, lower than the $25.0 \%$ and $21.1 \%$ reported among the Italians and Brazilians respectively $[4,7]$. The variation in the definitions of ADRs, differences in cut-off age for defining the elderly and the methods of identification of the ADRs in the studies could partly account for the variations in the findings of these studies.

In this study, cardiovascular medications and non-steroidal anti-inflammatory drugs (NSAIDs) were implicated in many of the ADRs among the study participants consistent with similar studies in England and Brazil [4,33]. In this study, diclofenac caused gastrointestinal (GIT) bleeding and acute kidney injury among the participants. Diclofenac is used for the management of pain conditions among the elderly, but it is considered a PIM in the 2015 AGS-Beers Criteria if used for an extended period without a gastroprotective agent. A previous study indicated that NSAIDs were responsible for a quarter of ADRs in each of the United Kingdom and the United States and were a major reason for admission in these countries [34]. Acute kidney injury is a serious ADR among the elderly which is less quantified with NSAIDs than the GIT effects [35], hence the need for physicians to be cautious and vigilant when prescribing this class of medications to the elderly population.

This present study found no significant association between the 2015 AGS-Beers PIMs and ADRs among the participants similar to studies that applied the 2012 version of the Criteria $[4,18,19]$. The lack of association between the 2015 AGS-Beers' PIMs and ADRs suggests that avoiding the Criteria' PIMs alone may not be adequate to reduce or prevent ADRs among Nigerian elderly inpatients. Other interventions including multi-disciplinary medication reviews involving pharmacists and geriatricians may be needed to reduce ADRs among this segment of the population.

A comprehension of the factors associated with ADRs among elderly inpatients can assist to optimize their medication therapy and improve clinical outcomes. In this study, the musculoskeletal disorders and the use of strong anticholinergic medications were predictors of ADRs, underpinning the significance of careful attention to these disorders and reducing anticholinergic burden when prescribing to the elderly. Medications with strong anticholinergic properties can cause peripheral effects such as dry mouth and eyes, constipation or urinary-retention and are associated with increased risk of mortality in the elderly population [36]. In this study, the diagnoses of chronic kidney disease and heart failure were not associated with ADRs in contrast with other studies [4, 6]. Although the duration of hospitalization was associated with ADRs in the bivariate analysis, it was no longer significant in the regression model. This 
result probably indicates that with good clinical practice, the duration of inpatient care may not be a determinant for ADR occurrence in the elderly. There was a negative association between age and ADRs in this study in contradiction of many studies $[3,4,33]$, probably due to the high proportion of participants in the lower age range which was a reflection of the young old population in Nigeria.

A few studies have applied the Beers Criteria to evaluate the quality of medicine prescribing among elderly Nigerians [21-23], however, to the best of these authors' knowledge, this was the first study to assess associations between the Beers PIMs and ADRs in this population. This study will, therefore, add to the existing information about the potential adverse effects of medicines among the elderly in Nigeria.

Limitations of the study

This study has some limitations including the retrospective nature of the study. Information such as laboratory data and medical history were missing in some patients' records. This limited the full application of the Criteria to all patients. The possibility exists that the PIMs may be higher than reported in this study. It is equally possible that the ADRs may have been underestimated since retrospective studies are known to detect lower ADRs compared to prospective evaluations [4]. Although adjustments were made for some cofounders in this study, it is possible that other cofounders existed that were not evaluated. The radio-imaging data such as ECG were not reviewed for ADRs, and this study was carried out in a teaching hospital which may limit generalizations to other healthcare facilities in the country.

\section{Conclusions}

The 2015 AGS-Beers Criteria PIMs were not significantly associated with ADRs among the hospitalized elderly in Nigeria similar to several other studies. This study finding indicates that avoiding the Criteria PIMs alone may not be sufficient in reducing ADRs among this group of patients. The diagnoses of musculoskeletal diseases and use of strong anticholinergic medications were independent factors for ADRs among the study participants. Prescribers should strive to reduce anticholinergic burden and be vigilant when prescribing medications for elderly inpatients with musculoskeletal disorders.

\section{References}

1. Obreli-Neto PR, Nobili A, de Oliveira Baldoni A, Guidoni CM, de Lyra Júnior DP, Pilger D, et al. Adverse drug reactions caused by drug-drug interactions in elderly outpatients: a prospective cohort study. Eur J Clin Pharmacol. 2012;68(12):1667-76.

2. Parameswaran Nair N, Chalmers L, Peterson GM, Bereznicki BJ, Castelino RL, Bereznicki LR. Hospitalisation in older patients due to adverse drug reactions -the need for a prediction tool. Clin Interv Aging. 2016;11:497-505.

3. Alhawassi TM, Krass I, Bajorek BV, Pont LG. A systematic review of the prevalence and risk factors for adverse drug reactions in the elderly in the acute care setting. Clinl Interv Aging. 2014; 9:2079-86. 
4. de Figueiredo TP, de Souza Groia RC, Barroso SCC, do Nascimento MMG, Reis AMM. Factors associated with adverse drug reactions in older inpatients in teaching hospital. IJCP. 2017; 39(4): 679-685.

5. Hamilton H, Gallagher P, Ryan C, Byrne S, O'Mahony D. Potentially inappropriate medications defined by STOPP Criteria and the risk of adverse drug events in older hospitalised patients. Arch Intern Med. 2011;171(11):1013-9.

6. O'Connor MN, Gallagher P, Byrne S, O'Mahony D. Adverse drug reactions in older patients during hospitalisation: are they predictable? Age Ageing. 2012;41(6):771-6.

7. Conforti A, Costantini D, Moretti U, Leone R, Grezzana M, Zanetti F. Adverse drug reactions in older patients: an Italian observational prospective hospital study. Drug Healthc Patient Saf. 2012:75.

8. American Geriatrics Society Beers Criteria Update Expert Panel. American Geriatrics Society 2015 Updated Beers Criteria for Potentially Inappropriate Medication Use in Older Adults. J Am Geriatr Soc. 2015;63(11):2227-46.

9. Renom-Guiteras A, Meyer G, Thurmann PA. The EU (7)-PIM list: a list of potentially inappropriate medications for older people consented by experts from seven European countries. Eur J Clin Pharmacol. 2015; 71(7): 861-875.

10. O'Mahony D, O'Sullivan D, Byrne S, O'Connor MN, Ryan C, Gallagher STOPP/START criteria for potentially inappropriate prescribing in older people: version 2. Age Ageing. 2015; 44(2): 213-218.

11. Laroche ML, Charmes JP, Nouaille Y, Picard N, Merie L. Is inappropriate medication use a major cause of adverse drug reactions in the elderly? Br J Clin Pharmacol. 2007; 63; 177-186.

12. Onder G, Landi F, Liperoti R, Flalova D, Gambassi G, Bernabel R. Impact of inappropriate drug use among hospitalized older adults. Eur J Clin Pharmacol. 2005; 61:453-459.

13. Budnitz DS, Shehab N, Kegler SR, Richards CL. Medication use leading to emergency department visits for adverse drug events in older adults. Ann Intern Med. 2007;147 (11):755-765.

14. Passarelli MC, Jacob-Filho W, Figueras A. Adverse drug reactions in an elderly hospitalized population: inappropriate prescription is a leading cause. Drug Aging. 2005; 22 (9):767-77.

15. Brown JD, Hutchison LC, Li C, Painter JT, Martin BC. Predictive Validity of the Beers and Screening Tool of Elderly Potentially Inappropriate Prescriptions (STOPP) Criteria to Detect Adverse Drug Events, Hospitalisations, and Emergency Department Visits in the United States. J Am Geriatr Soc. 2016; 64(1):22-30.

16. Reich O, Rosemann T, Rapold R, Blozik E, Senn O. Potentially inappropriate medication use in older patients in swiss managed care plans: prevalence, determinants and association with hospitalization. PloS one. 2014;9(8):e105425. Epub 2014/08/20. pmid:25136981

17. do Nascimento MM, Mambrini JV, Lima-Costa MF, Firmo JO, Peixoto SW, de Loyola Filho Al. Potentially inappropriate medications: predictor for mortality in a cohort of community-dwelling older adults. Eur J Clin Pharmacol. 2017; 73(5):615-621

18. Tosato M, Landi F, Martone AM, Cherubini A, Corsonello A, Volpato S, et al. Potentially inappropriate drug use among hospitalised older adults: results from the CRIME study. Age Ageing. 2014; 
43(6):767-73.

19. Pasina L, Djade CD, Tettamanti M, Franchi C, Salerno F, Corrao S, et al. Prevalence of potentially inappropriate medications and risk of adverse clinical outcome in a cohort of hospitalised elderly patients: results from the REPOSI Study. J Clin Pharm Ther. 2014;39(5):511-5.

20. Ishii S, Kojima K, Ezawa K, Higashi K, Ikebata Y, Takehisa $Y$ et al. The association of change in medication regimen and use of inappropriate medication based on beers criteria with adverse outcomes in Japanese long-term care facilities. Geriatr Gerontol Int. 2017;17(4):591-597.

21. Eze UIH, Olowu AO. Prescribing patterns and inappropriate use of Medications in Elderly Outpatients in a Tertiary Hospital in Nigeria Trop J Pharm Res. 2011; 10 (1): 19-25

22. Fadare JO, Desalu OO, Obimakinde AM, Adeoti AO, Agboola SM, Aina FO. Prevalence of inappropriate medication prescription in the elderly in Nigeria: A comparison of Beers and STOPP criteria. Int J Risk Saf Med.2015;27(4):177-89.

23. Akande-Sholabi W, Adebusoye LA, Olowookere OO. Potentially inappropriate medication use among older patients attending a geriatric centre in south-west Nigeria. Pharmacy Practice. 2018;16(3):1235.

24. United Nations DoEaSA. Population Division World Population Ageing 2017-Highlights (ST/ESA/SERA/397). 2017. Available from:

http://www.un.org/en/development/desa/population/.../ageing/WPA2017_Highlights.pdf. Accessed August 13, 2018.

25. Charan J, Biswas T. How to calculate sample size for different study designs in medical research? Indian J Psychol Med. 2013;35(2):121-6.

26. Charlson M, Szatrowski TP, Peterson J, Gold J. Validation of a combined comorbidity index. J Clin Epidemiol. 1994;47(11):1245-1251

27. Cockcroft DW, Gault MH. Prediction of creatinine clearance from serum creatinine. 1976; 16:31-41.

28. Griffin FA, Resar RK, Institute for Healthcare Improvement. IHI Global Trigger Tool for Measuring Adverse Events. Second ed. Cambridge, Massachusetts: IHI Innovation Series white paper; 2009. Available from https://oig.hhs.gov/.../IHI\%20Guidance\%20Document\%20-\%20Hospital\%20Trigger\%. Accessed August 13, 2018.

29. Belhekar MN, Taur SR, Munshi RP. A study of agreement between the Naranjo algorithm and WHOUMC Criteria for causality assessment of adverse drug reactions. Indian J Pharmacol. 2014;46(1).

30. Panel on Prevention of Falls in Elderly, American Geriatrics Society and British Geriatrics Society. Summary of the Updated American Geriatrics Society/British Geriatrics Society clinical practice guideline for prevention of falls in elderly. J Am Geriatr Soc.2011;59(1):148-57.

31. Tangiisuran B, Scutt G, Stevenson J, et al. Development and validation of a risk model for predicting adverse drug reactions in older people during hospital stay: Brighton Adverse Drug Reactions Risk (BADRI) model. PLoS One. 2014;9(10):e111254. 
32. Zhang X, Zhou S, Pan K, Li X, Zhao X, Zhou Y et al. Potentially inappropriate medications in hospitalized older patients: a cross-sectional study using the Beers 2015 criteria versus the 2012 criteria. Clin Interv Aging. 2017; 12: 1697-1703.

33. Tangiisuran B, Davies JG, Wright JE, Rajkumar C. Adverse drug reactions in a population of hospitalized very elderly patients. Drug Aging 2012; 29:453-62

34. Howard RL, Avery AJ, Slavenburg S, Royal S, Pipe G, Lucassen P, et al. Which drugs cause preventable admissions to hospital? A systematic review. Br J Clin Pharmacol. 2007;63(2):136-47.

35. Zhang X, Donnan PT, Bell S, Guthrie B. Non-steroidal anti-inflammatory drug induced acute kidney injury in the community dwelling general population and people with chronic kidney disease: systematic review and meta-analysis. BMC Nephrol. 2017;18(1).

36. Gutiérrez-Valencia M, Martínez-Velilla N, Vetrano DL, Corsonello A, Lattanzio F, Ladrón-Arana S, et al. Anticholinergic burden and health outcomes among older adults discharged from hospital: results from the CRIME study. Eur J Clin Pharmacol. 2017;73(11):1467-1474.

\section{Abbreviations}

ADRs $=$ Adverse drug reactions

AGS= American Geriatrics Society

PIMs=Potential inappropriate medicines

$\mathrm{PIP}=$ Potential inappropriate prescribing

\section{Declarations}

Ethics approval and consent to participate

This study utilized patients' medical records which were analysed retrospectively. The patients'

informed consents were therefore considered unnecessary. This study was approved as such by the Biomedical Research Ethics Committee (BREC) of University of KwaZulu-Natal under reference number BE 591/16 and the study hospital Ethical Review Committees under reference number OOUTH/HREC/97/2016. Permission from gate-keeper was also obtained from the head of the Medical Outpatients Department in the facility.

Consent to publish

Not applicable

Availability of data and materials

The datasets used and/or analysed during the current study are available from the corresponding 
author on reasonable request.

Competing interests

All the authors declared no conflict of interest with respect to the research, authorship, and or publication of the research

Funding statement

This research received no specific grant from any funding agency in the public, commercial or not-forprofit sectors.

Authors' contributions

SAS conceptualized the study, collected and analyzed the data and prepare the initial manuscript. SAS, FO and MN designed the study, read the manuscript for intellectual content and approved the final manuscript.

Acknowledgements

The authors will like to thank the Ms Carrin Martin for the language editing of the manuscript.

\section{Tables}

Table 1 - The socio-demographic characteristics of the study population 


\begin{tabular}{|c|c|c|c|}
\hline Variable & Grouping & Frequency & percentage \\
\hline \multirow[t]{2}{*}{ Age } & $60-79$ years & 228 & 85.1 \\
\hline & $\geq 80$ years & 40 & 14.9 \\
\hline \multirow[t]{2}{*}{ Gender } & Female & 122 & 45.5 \\
\hline & Male & 146 & 54.5 \\
\hline \multirow[t]{2}{*}{ Marital status } & Single & 109 & 40.7 \\
\hline & Married & 159 & 59.3 \\
\hline \multirow[t]{4}{*}{ Education qualification } & No formal education & 138 & 51.5 \\
\hline & Primary & 60 & 22.4 \\
\hline & Secondary & 39 & 14.5 \\
\hline & Post-secondary & 31 & 11.6 \\
\hline \multirow[t]{3}{*}{ Employment status } & Private & 158 & 58.9 \\
\hline & Public & 4 & 1.5 \\
\hline & Retired & 106 & 39.6 \\
\hline \multirow[t]{3}{*}{ Number of chronic diseases } & None & 27 & 10.1 \\
\hline & One disease & 233 & 86.9 \\
\hline & $\geq$ two diseases & 8 & 3.0 \\
\hline \multirow[t]{4}{*}{ Hospitals attended prior to admission } & Private clinics & 67 & 25.0 \\
\hline & $\mathrm{PHC}$ & 32 & 11.9 \\
\hline & $\mathrm{SHC}$ & 87 & 32.5 \\
\hline & THC & 82 & 30.6 \\
\hline \multirow[t]{8}{*}{ Diagnosis at admission } & Diseases of circulatory system & 111 & 41.4 \\
\hline & Musculoskeletal disorders & 23 & 8.6 \\
\hline & Neoplasm & 24 & 9.0 \\
\hline & Infectious diseases & 23 & 8.6 \\
\hline & Genitourinary disorders & 22 & 8.2 \\
\hline & Digestive disorders & 18 & 6.7 \\
\hline & Endocrine disorders & 10 & 3.7 \\
\hline & Others & 37 & 13.8 \\
\hline
\end{tabular}

$\mathrm{PHC}=$ primary healthcare, $\mathrm{SHC}=$ secondary healthcare, $\mathrm{THC}=$ tertiary healthcare Others include Other systems include skin, respiratory, nervous, mental, and behavioral, eye diseases and diseases affecting more than 1 system.

Table 2- PIM according to chemical and pharmacological classification

\begin{tabular}{lll}
\hline Medicine classification & Frequency & Percentage \\
\hline Non-steroidal anti-inflammatory drugs & 20 & 23.2 \\
Cardiovascular agents & 31 & 36.0 \\
Anticholinergics & 12 & 14.0 \\
Opioids & 10 & 11.6 \\
Benzodiazepines & 6 & 7.0 \\
Anti-diabetes & 4 & 4.7 \\
Anti-emetics & 2 & 2.3 \\
Corticosteroid & 1 & 1.2 \\
Total & 86 & 100.0 \\
\hline
\end{tabular}


Table 3: Prevalence of ADRs and the offending medications among the study population

\begin{tabular}{|c|c|c|}
\hline Systems affected by the ADRs & $\mathrm{n}(\%)$ & Offending medication \\
\hline Digestive system & $22(51.2)$ & \\
\hline \multirow[t]{2}{*}{ Constipation } & 7 & Chlorpromazine (1), Tramadol (3), \\
\hline & & Diclofenac (2), Amitriptyline (1) \\
\hline \multirow[t]{2}{*}{ Vomiting } & 5 & Tramadol (1), pentazocine (2), \\
\hline & & atorvastatin (1), digoxin (1) \\
\hline \multirow[t]{2}{*}{ Diarrhea } & 5 & Ceftriaxone (2), isoniazid (1), \\
\hline & & Lisinopril (1), diclofenac (1) \\
\hline GIT bleeding & 5 & Diclofenac (4), Aspirin (1) \\
\hline Vascular system & $10(23.3)$ & \\
\hline Hyperkalemia & 5 & Lisinopril (3), digoxin (2) \\
\hline Hypotension & 3 & Methyldopa (2), Nifedipine (1) \\
\hline Epistaxis & 1 & Warfarin (1) \\
\hline Thrombocytosis & 1 & Heparin (1) \\
\hline Endocrine system & $3(7.0)$ & \\
\hline Hypoglycemia & 3 & Insulin (3) \\
\hline Genitourinary system & $2(4.7)$ & \\
\hline Acute kidney injury & 1 & Diclofenac (1) \\
\hline Urinary retention & 1 & Timolol (1) \\
\hline Nervous system & $5(11.6)$ & \\
\hline Encephalopathy & 1 & Furosemide (1) \\
\hline Fall & 1 & Tramadol (1) \\
\hline Gait impairment & 1 & Amitriptyline (1) \\
\hline Complex partial seizure & 1 & Chlorpromazine (1) \\
\hline Sedation & 1 & Bromazepam (1) \\
\hline Cutaneous(skin) & $1(2.3)$ & \\
\hline Stephen Johnson syndrome & 1 & Spironolactone (1) \\
\hline Total & $43(100.0)$ & \\
\hline
\end{tabular}

legend: $\mathrm{ADR}=$ Adverse drug reaction, $\mathrm{GIT}=$ gastrointestinal tract

Table 4: Associations of the independent variables with ADRs in the bivariate and logistic regression 


\begin{tabular}{|c|c|c|c|c|c|c|c|c|c|}
\hline \multirow{2}{*}{$\begin{array}{l}\text { Variable } \\
\text { Age (yrs) }\end{array}$} & Grouping & $\begin{array}{l}\text { No } \\
A D R\end{array}$ & $A D R$ & \multicolumn{2}{|c|}{$\begin{array}{l}\text { Crude odd } \\
\text { ratio (95\% CI) }\end{array}$} & \multirow{2}{*}{$\begin{array}{l}p \text {-value } \\
0.45\end{array}$} & \multicolumn{2}{|c|}{$\begin{array}{l}\text { Adjusted odd } \\
\text { ratio }(95 \% C I)\end{array}$} & \multirow{2}{*}{$\begin{array}{l}p \text {-value } \\
0.93\end{array}$} \\
\hline & $60-79$ & 195 & 33 & 0.66 & $(0.22-$ & & $\begin{array}{l}1.06 \\
379)\end{array}$ & $(0.30-$ & \\
\hline & $\geq 80$ & $36(13.4)$ & $\begin{array}{l}4 \\
(1.5)\end{array}$ & & & & & & \\
\hline \multirow[t]{2}{*}{ Gender } & Female & $\begin{array}{l}104 \\
(38.8)\end{array}$ & $\begin{array}{l}18 \\
(6.7)\end{array}$ & $\begin{array}{l}0.86 \\
1.73)\end{array}$ & $(0.43-$ & 0.68 & $\begin{array}{l}0.94 \\
2.03)\end{array}$ & $(0.44$ & 0.88 \\
\hline & Male & $\begin{array}{l}127 \\
(47.4)\end{array}$ & $\begin{array}{l}19 \\
(7.1)\end{array}$ & & & & & & \\
\hline \multirow[t]{2}{*}{ Comorbidity index } & $<4.0$ & $85(31.7)$ & $\begin{array}{l}19 \\
(7.1)\end{array}$ & $\begin{array}{l}0.52 \\
1.11)\end{array}$ & $(0.27-$ & 0.09 & $\begin{array}{l}0.52 \\
1.13)\end{array}$ & $(0.24-$ & 0.10 \\
\hline & $\geq 4.0$ & $\begin{array}{l}146 \\
(54.5)\end{array}$ & $\begin{array}{l}18 \\
(6.7)\end{array}$ & & & & & & \\
\hline \multirow[t]{2}{*}{$\begin{array}{l}\text { Musculoskeletal } \\
\text { disorder }\end{array}$} & Yes & $13(4.9)$ & $\begin{array}{l}10 \\
(3.7)\end{array}$ & $\begin{array}{l}6.21 \\
15.53)\end{array}$ & $(2.48-$ & $<0.001 *$ & $\begin{array}{l}7.38 \\
20.34)\end{array}$ & $(2.68-$ & $<0.001^{* *}$ \\
\hline & No & $\begin{array}{l}218 \\
(81.3)\end{array}$ & $\begin{array}{l}27 \\
(10.1)\end{array}$ & & & & & & \\
\hline \multirow[t]{2}{*}{ Heart failure } & Yes & $24(9.0)$ & $\begin{array}{l}6 \\
(2.2)\end{array}$ & $\begin{array}{l}0.65 \\
1.43)\end{array}$ & $(0.30-$ & 0.30 & $\begin{array}{l}2.04 \\
5.87)\end{array}$ & $(0.71-$ & 0.19 \\
\hline & No & $\begin{array}{l}207 \\
(77.2)\end{array}$ & $\begin{array}{l}31 \\
(11.6)\end{array}$ & & & & & & \\
\hline \multirow[t]{2}{*}{ Kidney disease } & Yes & $20(7.5)$ & $\begin{array}{l}3 \\
(1.1)\end{array}$ & $\begin{array}{l}1.05 \\
3.20)\end{array}$ & $(0.35-$ & 0.91 & $\begin{array}{l}1.68 \\
6.67)\end{array}$ & $(0.42-$ & 0.46 \\
\hline & No & $\begin{array}{l}211 \\
(78.7)\end{array}$ & $\begin{array}{l}34 \\
(12.7)\end{array}$ & & & & & & \\
\hline \multirow[t]{2}{*}{ PIM } & Yes & $71(26.5)$ & $\begin{array}{l}15 \\
(5.6)\end{array}$ & $\begin{array}{l}0.69 \\
1.27)\end{array}$ & $(0.38-$ & 0.24 & $\begin{array}{l}1.35 \\
2.89)\end{array}$ & $(0.63-$ & 0.44 \\
\hline & No & $\begin{array}{l}160 \\
(59.7)\end{array}$ & $\begin{array}{l}22 \\
(8.2)\end{array}$ & & & & & & \\
\hline \multirow[t]{2}{*}{$\begin{array}{l}\text { Falls } \\
\text { medications }\end{array}$} & Yes & $31(11.6)$ & $\begin{array}{l}8 \\
(3.0)\end{array}$ & $\begin{array}{l}0.56 \\
1.34)\end{array}$ & $(0.24-$ & 0.19 & $\begin{array}{l}1.03 \\
2.81)\end{array}$ & $(0.38-$ & 0.95 \\
\hline & No & $\begin{array}{l}200 \\
(74.6)\end{array}$ & $\begin{array}{l}29 \\
(10.8)\end{array}$ & & & & & & \\
\hline \multirow[t]{2}{*}{$\begin{array}{l}\text { Strong anti-cholinergic } \\
\text { medications }\end{array}$} & Yes & $9(3.4)$ & $\begin{array}{l}4 \\
(1.5)\end{array}$ & $\begin{array}{l}2.99 \\
10.26)\end{array}$ & $(0.87-$ & 0.08 & $\begin{array}{l}4.02 \\
15.58)\end{array}$ & $(1.04-$ & $0.04^{* *}$ \\
\hline & No & $\begin{array}{l}222 \\
(82.8)\end{array}$ & $\begin{array}{l}33 \\
(12 . \\
3)\end{array}$ & & & & & & \\
\hline $\begin{array}{l}\text { Duration } \\
\text { hospitalization }\end{array}$ & $\begin{array}{l}<12 \\
\text { days } \\
\geq 12 \\
\text { days }\end{array}$ & $\begin{array}{l}157 \\
(58.6) \\
74(27.6)\end{array}$ & $\begin{array}{l}19 \\
(7.1) \\
18 \\
(6.7) \\
\end{array}$ & $\begin{array}{l}2.01 \\
4.05)\end{array}$ & $(1.00-$ & $0.048^{*}$ & $\begin{array}{l}1.88 \\
4.02)\end{array}$ & $(0.88-$ & 0.10 \\
\hline
\end{tabular}

*significant in bivariate analysis **significant in the logistic regression at $p<0.05$

Figures 


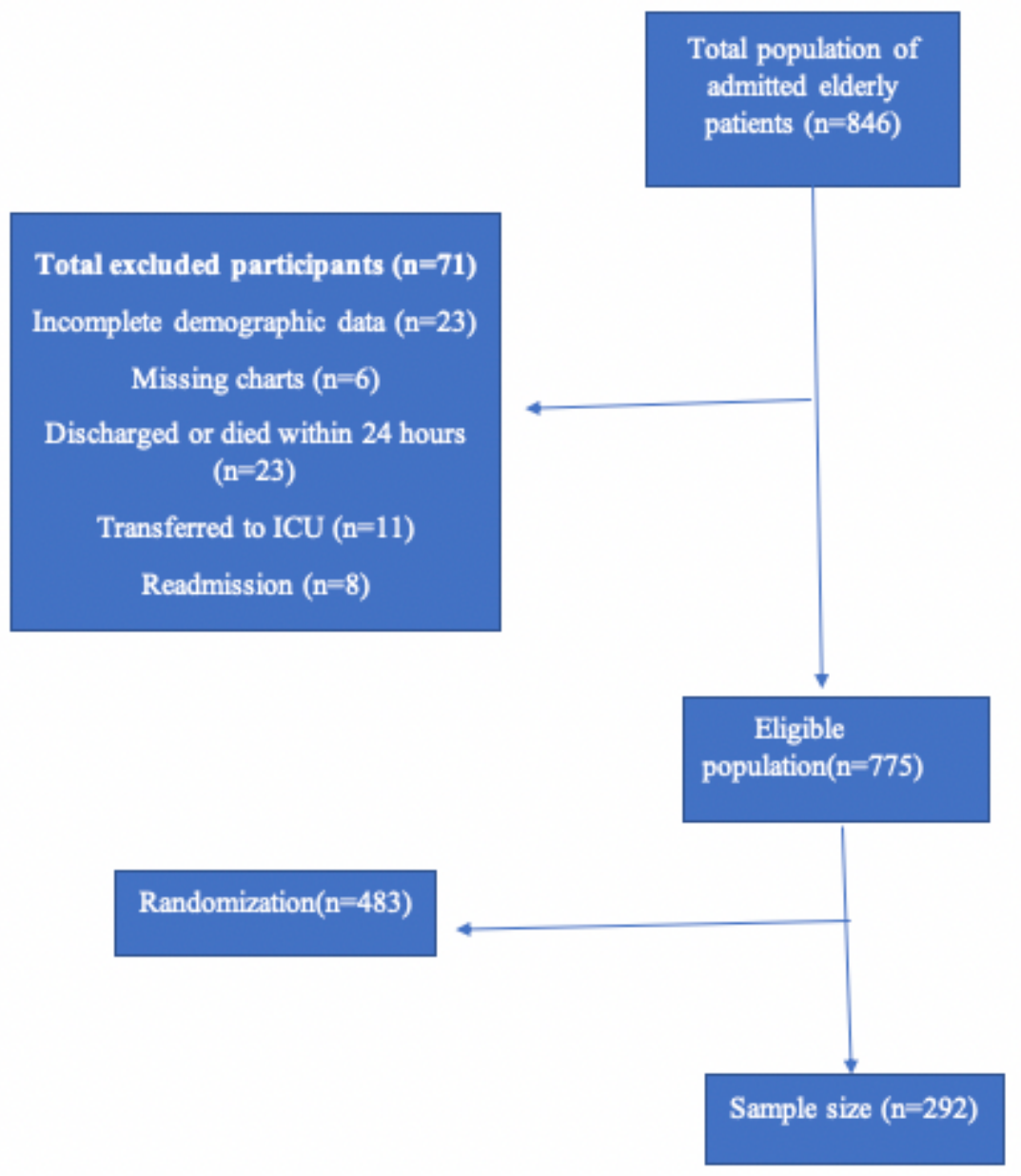

Figure 1: Flowchart depicting the process of selection for the participants

\section{Figure 1}

Participant selection

\section{Supplementary Files}

This is a list of supplementary files associated with this preprint. Click to download.

- SUPPLEMENTBMC.docx 